\title{
Paranoia Among Children Due to COVID-19 Outbreak
}

\section{IJCRR}

Section: Healthcare

Sci. Journal Impact

Factor: $6.1(2018)$

ICV: 90.90 (2018)

(c) (i) (8)

Copyright@IJCRR

\section{Charanya Suresh' ${ }^{1}$ Anitha Roy ${ }^{2}$ Muralidharan N. P. ${ }^{3}$}

\section{ABSTRACT}

Aim and Background: The 2019 Coronavirus Disease (COVID-19) has caused universal psychosocial effects due to mass hysteria, economic burden, and financial losses along with its high infectivity and fatality rates. COVID-19 mass fear, called "coronaphobia," has created a multitude of psychiatric manifestations across the various strata of society. So this analysis was carried out to describe the psychological impact of COVID-19 on people, more specifically children.

Materials and Methods: The following main words are searched for PubMed and Google Scholar: "COVID-19," "SARS-CoV2," "Pandemic," "Psychology," "Psychology," "Psychiatry," "Marginalized," "Telemedicine," "Mental Health," "Quarantine," "Infodemic," "Social Media" and "Internet." There were also several newspaper stories pertaining to COVID-19 and psychosocial impacts added as per context.

Results and Discussion: Long-term acute panic, anxiety, repetitive habits, hoarding, hysteria, depression, and post-traumatic stress disorder (PTSD) may be triggered by the disease itself compounded by compulsory quarantine to fight COVID-19 introduced by national lockdowns. These were fuelled by an "infodemic" spread through various social media platforms. Communitybased COVID-19 prevention services can interrupt the normal lifestyle of children, and can cause florid mental distress. Children's psychosocial factors are influenced in many ways by this pandemic and require special consideration.

Conclusion: Psychosocial crisis management and intervention models should be implemented urgently by the government, health care professionals, and other stakeholders in order to better cope with these psychosocial problems from various strata of society. The use of internet resources, technology, and social media in order to combat both pandemic and infodemic needs to be introduced. Psychosocial preparedness by the establishment of mental organizations specific for future pandemics is certainly necessary.

Key Words: Anxiety, Children, Paranoia, Psychological impact, COVID-19, Pandemic

\section{INTRODUCTION}

The coronavirus disease 2019 (COVID-19) episode was declared a general wellbeing crisis of universal concern by the World Health Organization (WHO) on 30 January, 2020 when 34 districts of China had instances of disease, and the absolute case tally outperformed that of the serious intense respiratory disorder (SARS) of 2003. It has started from Wuhan of Hubei Province in late December 2019 and the number of cases expanded exponentially inside and past Wuhan. The prime objective of the entire world now is to focus on decreasing the transmission and financial impact of the 2019 novel coronavirus (COVID-19) pandemic ${ }^{1}$. In this quickly evolving circumstance, media and social discussions are totally ruled by the outbreak, and kids are presented to a lot of data and significant levels of pressure and uneasiness around them. Moreover, children are encountering significant changes to their every day normal and social framework, which customarily encourage flexibility to test occasions ${ }^{2}$.

Guardians would effectively shield their children from trouble and may abstain from discussing troublesome emotions and occasions. Studies show that even kids as young as 2 years know about the progressions around them ${ }^{3}$. The understanding of children advances all through youth and preadulthood. Along these lines, when adults converse with

\section{Corresponding Author:}

Dr. Anitha Roy, Associate Professor, Department of Pharmacology, Saveetha Dental College, Saveetha Institute of Medical and Technical Sciences, Saveetha University, 162, Poonamallee High Road, Chennai-600077, Tamil Nadu, India; Ph: +91- 9840787458; Email: anitharoy@ saveetha.com

ISSN: 2231-2196 (Print)

Received: 25.08 .2020
ISSN: $0975-5241$ (Online)

Revised: 22.09 .2020
Accepted: 20.10 .2020
Published: 03.11 .2020 
children, the data shared with them should consider the age of children and level of comprehension. Touchy and powerful correspondence about the dangerous diseases could have a significant impact on their mental prosperity ${ }^{4}$.

The idea for this review stemmed from the current interest in the community. Moreover, detachment from guardians or parental misfortune during adolescence additionally has significant emotional consequences, including a higher danger of creating disposition issues and psychosis, and demise by self-destruction in adulthood. The age of the underlying division is known to be pertinent to the mental turn of events. The parent-kid relationship depends on the genuineness of parent communication. Kids need fair data about changes in their family; when this data is missing, kids struggle to understand the circumstance all alone. Understanding child psychology is important to ensure a viable source of information for their child. It should neither disparage nor overestimate the comprehension of the child ${ }^{5}$.

\section{WIDESPREAD PANIC AND PARANOIA}

The unprecedented anxiety due to the sudden occurrence of a pandemic is justified because it depicts avoiding potential risk against contracting or spreading the infection as the sole prevention $^{6}$. The hyper-fast transmission process has been gradually driving COVID-19 tension to a point where it might be counterproductive ${ }^{7}$.

An increasingly significant yet handily ignored issue is the mental effect on children and teenagers. Stressors, for example, delayed span, fears of contamination, dissatisfaction and weariness, insufficient data, absence of in-person contact with colleagues, companions, and instructors, absence of individual space at home, and family money related misfortune can have many progressively tricky and suffering impacts on kids. A research conducted by Sprang and Silman indicated that the mean posttraumatic stress scores were multiple times higher in youngsters who had been isolated.

Besides, the connection between lifestyle changes and psychosocial stress brought about by quarantine could additionally exasperate the unfavorable impacts on a kid's physical and emotional well-being, which could cause an endless loop. To moderate the results of quarantine, the administration, non-legislative associations (NGOs), the network, school, and guardians should know about the drawback of the circumstance and attempt to viably address these issues right away. Encounters gained from past flare-ups can be important for planning another program to handle these issues throughout the world ${ }^{8}$.

\section{FEAR AND ANXIETY AMONG CHILDREN}

Torrents of uncertainty and an absence of clarity leading to unfamiliarity even to basic health questions such as the risk of becoming infected or severely ill appears to heighten the dread and tension among the kids, making them an under-educated community ${ }^{9}$. Children need legit data about changes inside their family; when this data is missing, children endeavor to understand the circumstance all alone.

Knowledge of the formative stage of children is important to ensure that parents neither underestimate nor overestimate understanding. While communicating with young should consider children's perception of sickness and causality. Between the age of 4 and 7 years, understanding is generously impacted by mysterious reasoning. Inconsequential activities can alter the mental health of children; an ailment can be brought about by a specific idea or conduct ${ }^{10}$.

The rise of supernatural intuition happens around a similar time children are building up a feeling of soul, while as yet having a poor comprehension of how ailment is spread. Adults should be careful that youngsters are not improperly accusing themselves or feeling that the disease is a discipline for past terrible behavior ${ }^{11}$. Therefore, tuning in to what kids accept about COVID-19 transmission is crucial; furnishing kids with an exact clarification that is significant to them will ensure that they don't feel pointlessly scared or blameworthy ${ }^{12}$.

\section{JUVENILE RESPONSE TO PANDEMIC}

The fear of uncertainty about 'what could be coming' and 'how tragic it would be' structures a fundamental piece of a child's response. India is perceived as a general public that likes to plan, colossal disturbance to customary everyday practice, tends to elevate the nervousness among children.

Emotional reactions to past crises and catastrophes have influenced the board of mental medical aid, concentrating on psycho-education about regularizing responses and adapting procedures. Providing data and organizing correspondence with youngsters about COVID-19 is a fundamental segment of any all-inclusive, network-driven reaction to the pandemic. ${ }^{3}$

Amplifying the pressing mental needs of the people by disregarding the mental impacts of COVID-19, particularly for kids and youngsters, who represent $42 \%$ of the world's population, could end up being fatal. The effect of COVID-19 will be felt hardest by the world's most vulnerable population like the children. Numerous effectively live in neediness, and the results of the COVID-19 reaction would put them into further hardship. ${ }^{6}$

\section{IMPACT OF PSYCHOLOGICAL MECHANISMS}

The effect of such a clueless pandemic could develop as a significant threat to normal mental health ${ }^{13}$. During a pandemic, individuals tend to go out of their way to equip themselves, which creates further anxiety among children. Hence, it could have the potential to scar the mental health of the child ${ }^{14}$.

Children flourish when they are sheltered and ensured, when family and network associations are steady and sustaining, 
and when their fundamental needs are met. The coronavirus pandemic and the remarkable measures to contain its spread are disturbing almost their life: their wellbeing, advancement, learning, conduct, their families' monetary security, and their insurance from savagery and abuse.

Adults should be sensitive to the vulnerability and mental difficulties of the children during a pandemic, without overpowering children with their own feelings of fear. This genuineness not just offers a rational clarification for what kids are watching, yet in addition awards authorization for kids to securely discuss their own feelings. Normalizing their passionate responses and consoling kids about how the family will care for one gives mutual peace.

\section{RELATIONSHIP BETWEEN PSYCHOLOGICAL MECHANISMS AND NOVEL CORONAVIRUS}

Children in the end become helpless to the danger of holding two clashing thoughts in their brain and steady extrapolating questionable theories about the pandemic which might act as a genuine hazard to a nation and its economy ${ }^{15}$. The vulnerability of the individual and worldwide impacts of COVID-19 is making incredible distress, notwithstanding the particular mental impact of quarantine. Adults' distraction with the ramifications of COVID-19 may compromise their capacity to delicately perceive and react to kids' signs or distress ${ }^{16}$. Children are receptive to adults' enthusiastic states and are exposed to unexplained and flighty conduct which is observed as a danger by them, bringing about a condition of tension ${ }^{7}$. Indeed, even kids younger than 2 years understand the absence of normal parental figures (eg, grandparents) and become agitated. ${ }^{17,18}$.

\section{CRISIS DUE TO DISRUPTED MANAGEMENT}

Disrupted administration encourages discussions about the infection, which permits sentimentality and falsehood to spread, and eventually, deception could talk its way through an uncommon danger. Deluding content spreads quicker than these stages can battle ${ }^{19,20}$. Children are investing more energy online because of school shutdowns and might be on edge or forlorn due to segregation and repression, making them progressively helpless against online predators ${ }^{21}$.

It is critical to keep this pandemic from being prevented from transforming into an emergency of child abuse. Governments need to represent the exceptional dangers of young girls and helpless kids, including the individuals who face segregation and disgrace, when anticipating social removal and other COVID-19 reaction measures ${ }^{22}$. Also, it is similarly imperative to help children who might be incidentally isolated from their folks because of ailment, just as those denied their freedom, and work together to get ready for a flood of kids looking for remote security and psychological wellness arrangements. ${ }^{8}$
Unsupervised psychological trauma in children due to a public health emergency could lead to various diseases and disorders in the future. Hence, it is important to explore possible remedial interventions as well. Previously our team had conducted numerous in -vitro and in-vivo studies to explore and isolate the pharmacological profile of various plant extract as well as ${ }^{23,24}$ extensive studies on the pharmacological effects of nanoparticles ${ }^{25-29}$, analyzed the cytotoxic activity of various potent compounds ${ }^{30-32}$, carried out significant in-vitro studies ${ }^{23,33}$, threw some critical light on potential pharmaceutical agents ${ }^{33,34,35}$ and investigated various drug delivery approaches ${ }^{36,37}$ over the past 5 years.

\section{PUBLIC FEAR MANAGEMENT}

It is imperative to act to assemble and activate open and private assets to help the psychological wellness and psychosocial prosperity of the world's most powerless kids and youngsters at this remarkable time..$^{10}$ Here are four mechanisms by which children can be secured from the possibly destroying mental effect of this pandemic:

1. Prompt open and private interests in psychological wellness and psychosocial administrations and projects for youngsters, all through their childhoods particularly in low-asset settings.

2. Network-based arrangement, programming, and administration adjusted to the particular needs of youngsters and youngsters under pandemics such as COVID-19. UNICEF is presently coordinating emotional wellness and psychosocial support in various manners like learning for kids who are out of school, to supporting the psychological well-being of bleeding-edge laborers, to proactively contacting youngsters who show the indications of previous emotional well-being conditions, to utilizing innovation to straightforwardly arrive at those kids who need backing and advising. With workplaces across 192 nations, in an assortment of settings, UNICEF stands prepared to help governments and specialists as they structure and actualize these measures.

3. Remembering the necessities of children for any conversation or usage of lockdowns or regulation measures. It is important to assemble children and teenagers straightforwardly, tune in to their requirements, and shape projects and administrations around these necessities.

4. Emotional well-being experts ought to set up proofbased rules and simple operational techniques to adapt to COVID-19 pandemic-related psychological wellness issues in youngsters. It is important to accept that the emotional well-being of children can be improved through cooperative systems that are set up across the nation that consists of specialists, psychotherapists, scientists, and network volunteers. Moreover, the post-pandemic reconnaissance of mental issues among these kids ought to be thought of. ${ }^{13}$ Most of 
the nations including the United States of America have adopted numerous combined initiatives to control, treat and prevent COVID-19 ${ }^{38}$.

\section{CONCLUSION}

It is extremely important to set up mental health organizations specific to future pandemics, with branches in many nations. Individual healthcare institutions for research, delivery of mental health, and coordination of awareness campaigns at both personal and community levels also should be there to manage such situations. Standardized websites and toll-free helpline numbers can help to relieve psychological distress among people regarding the present pandemic. Social media should be used in good sense to inform people about patterns of transmission, disease symptoms, and time when specific medical consultations are needed. Strict government regulations should be enforced to protect social media from devaluations and to have regulation on fake news, social media speculation, and misinformation. The COVID-19 pandemic taught explicitly how a "virus" can negatively impact human lives even in the 21 st century and simultaneously made to realize that the greatest assets of mankind are health, peace, love, solidarity, ingenuity, and knowledge.

\section{ACKNOWLEDGMENT}

Authors acknowledge the immense help received from the scholars whose articles are cited and included in references to this manuscript. The authors are also grateful to authors / editors / publishers of all those articles, journals, and books from which the literature for this article has been reviewed and discussed.

\section{Conflict of Interest: Nil}

Source of Funding: Nil

\section{REFERENCES}

1. Canady VA. MH leaders, insurers unite on COVID-19 resource toolkit. Mental Health Weekly. 2020 Apr 13;30 (15):3-5.

2. Balasubramanian M. Covid 19-The New Age Pandemic. Notion Press; 2020 May 19,51:102147.

3. Gournay K. COVID-19: impact on the population, the mental health of society and mental health nurses. British Journal of Mental Health Nursing. 2020 Apr 2;9(2):1-2.

4. Heimer R, McNeil R, Vlahov D. A community responds to the COVID-19 pandemic: a case study in protecting the health and human rights of people who use drugs. Journal of Urban Health. 2020 Aug;97(4):448-56.

5. Weible CM, Nohrstedt D, Cairney P, Carter DP, Crow DA, Durnová AP, Heikkila T, Ingold K, McConnell A, Stone D. COVID-19 and the policy sciences: initial reactions and perspectives. Policy sciences. 2020 Apr 18:1-7.
6. Mancini A. Heterogeneous Mental Health Consequences of COVID-19: Costs and Benefits; 2020 May 19,51:102147.

7. Li W, Yang Y, Liu Z-H, Zhao Y-J, Zhang Q, Zhang L, et al. Progression of Mental Health Services during the COVID-19 Outbreak in China. Int J Biol Sci . 2020 Mar 15;16(10):1732-8.

8. Depoux A, Martin S, Karafillakis E, Preet R, Wilder-Smith A, Larson $\mathrm{H}$. The pandemic of social media panic travels faster than the COVID-19 outbreak. J Travel Med. 2020 May 18; 27(3): taaa031.

9. Omary A. The COVID-19 Pandemic Mental Health Crisis Ahead; 2020 Jun;7(6):547-60.

10. Ho CS, Chee CY, Ho RC. Mental Health Strategies to Combat the Psychological Impact of COVID-19 Beyond Paranoia and Panic. Ann Acad Med Singapore. 2020 Mar 16;49(3):155-60.

11. Roy D, Tripathy S, Kar SK, Sharma N, Verma SK, Kaushal V. Study of knowledge, attitude, anxiety \& perceived mental healthcare need in Indian population during COVID-19 pandemic. Asian Journal of Psychiatry. 2020 Apr 8:102083.

12. Rajkumar RP. COVID-19 and mental health: A review of the existing literature. Asian journal of psychiatry. $2020 \mathrm{Apr}$ 10:102066.

13. Zhou X, Snoswell CL, Harding LE, Bambling M, Edirippulige $\mathrm{S}$, Bai X, Smith AC. The role of telehealth in reducing the mental health burden from COVID-19. Telemedicine and e-Health. 2020 Apr 1;26(4):377-9

14. Ransing R, Ramalho R, Orsolini L, Adiukwu F, Gonzalez-Diaz JM, Larnaout A, et al. Can COVID-19 related mental health issues be measured?: Assessment options for mental health professionals. Brain Behav Immun. 2020 May 26; 51:101990.

15. Greenberg N, Brooks SK, Wessely S, Tracy DK. How might the NHS protect the mental health of health-care workers after the COVID-19 crisis? Lancet Psychiatry. 2020 May 28; 725:138277.

16. Grover S, Dua D, Sahoo S, Mehra A, Nehra R, Chakrabarti S. Why all COVID-19 hospitals should have mental health professionals: The importance of mental health in a worldwide crisis! Asian J Psychiatr . 2020 May 5;51:102147.

17. Goldust M, Agarwal K, Kroumpouzos G, Jafferany M, Lotti T, Podder I. Mental Health Status of Dermatologists during the COVID-19 Pandemic; A Technology-based Therapy. Dermatol Ther. 2020 May 31;e13723.

18. Zandifar A, Badrfam R. Iranian mental health during the COVID-19 epidemic. Asian J Psychiatr . 2020 Mar 4;51:101990.

19. Yang Y, Li W, Zhang Q, Zhang L, Cheung T. Mental health services for older adults in China during the COVID-19 outbreak. Lancet. 2020; 13(9):15-9.

20. Holmes EA, O'Connor RC, Perry VH, Tracey I, Wessely S, Arseneault L, et al. Multidisciplinary research priorities for the COVID-19 pandemic: a call for action for mental health science. Lancet Psychiatry. 2020 Jun;7(6):547-60.

21. Health Organization W. Mental health and psychosocial considerations during the COVID-19 outbreak, 18 March 2020. 2020; available@https:/www.who.int/docs/default-source/coronaviruse/mental-health-considerations.pdf

22. Vellingiri B, Jayaramayya K, Iyer M, Narayanasamy A, Govindasamy V, Giridharan B, et al. COVID-19: A promising cure for the global panic. Sci Total Environ. 2020 Jul 10;725:138277.

23. Anitha R, Ashwini S. Antihyperglycemic activity of Caralluma fimbriata: An In vitro approach. Pharmacogn Mag . 2017 Oct; 13 (Suppl 3):S499-504.

24. Ezhilarasan D. Oxidative stress is bane in chronic liver diseases: Clinical and experimental perspective. Arab J Gastroenterol. 2018 Jun; 19 (2):56-64. 
25. Menon S, Ks SD, R S, S R, S VK. Selenium nanoparticles: A potent chemotherapeutic agent and an elucidation of its mechanism. Colloids Surf B Biointerfaces. 2018 Oct 1;170:280-92.

26. Rajeshkumar S, Kumar SV, Ramaiah A, Agarwal H, Lakshmi T, Roopan SM. Biosynthesis of zinc oxide nanoparticles usingMangifera indica leaves and evaluation of their antioxidant and cytotoxic properties in lung cancer (A549) cells. Enzyme Microb Technol. 2018 Oct;117:91-5.

27. Karthiga P, Rajeshkumar S, Annadurai G. Mechanism of Larvicidal Activity of Antimicrobial Silver Nanoparticles Synthesized Using Garcinia mangostana Bark Extract. J Cluster Sci. 2018 Nov 1;29(6):1233-41.

28. Rajeshkumar S. Synthesis of Zinc oxide nanoparticles using algal formulation (Padina tetrastromatica and Turbinaria conoides) and their antibacterial activity against fish pathogens. Res J Biotechnol. 2018;13(9):15-9.

29. Rajeshkumar S, Agarwal H, Kumar SV, Lakshmi T. Brassica oleracea mediated synthesis of zinc oxide nanoparticles and its antibacterial activity against pathogenic bacteria. Asian J Chem. 2018;30(12):2711-5.

30. Gheena S, Ezhilarasan D. Syringic acid triggers reactive oxygen species-mediated cytotoxicity in HepG2 cells. Hum Exp Toxicol. 2019 Jun 1;38(6):694-702.

31. Ezhilarasan D, Sokal E, Najimi M. Hepatic fibrosis: It is time to go with hepatic stellate cell-specific therapeutic targets. Hepatobiliary Pancreat Dis Int. 2018 Jun;17(3):192-7.
32. Ashwini S, Ezhilarasan D, Anitha R. Cytotoxic effect of Caralluma fimbriata against human colon cancer cells. Pharmacogn. J. 2017; 9(2): 204-07.

33. Perumalsamy H, Sankarapandian K, Veerappan K, Natarajan S, Kandaswamy N, Thangavelu L, et al. In silico and in vitro analysis of coumarin derivative induced anticancer effects by undergoing intrinsic pathway mediated apoptosis in human stomach cancer. Phytomedicine . 2018 Jul 15;46:119-30.

34. Lakshmi T, Krishnan V, Rajendran R, Madhusudhanan N. Azadirachta indica: A herbal panacea in dentistry - An update. Pharmacogn Rev. 2015 Jan; 9(17):41-4.

35. Lakshmi T, Ezhilarasan D, Nagaich U, Vijayaragavan R. Acacia catechu Ethanolic Seed Extract Triggers Apoptosis of SCC-25 Cells. Pharmacogn Mag. 2017 Oct;13(Suppl 3):S405-11.

36. Sharma P, Mehta M, Dhanjal DS, Kaur S, Gupta G, Singh H, et al. Emerging trends in the novel drug delivery approaches for the treatment of lung cancer. Chem Biol Interact 2019 Aug 25;309:108720.

37. Mehta M, Deeksha, Tewari D, Gupta G, Awasthi R, Singh H, et al. Oligonucleotide therapy: An emerging focus area for drug delivery in chronic inflammatory respiratory diseases. Chem Biol Interact. 2019 Aug 1; 308:206-15.

38. Kannamani Ramasamy. The war of United States of America with COVID-19. Int J Cur Res and Rev. 2020 August, 12 (16): 18-28. 